\title{
Pattern of utilization of blood and blood components in obstetrics at a tertiary care center: a cross-sectional study
}

\author{
Alpana Jacob*, Sunita Goyal, Tapasya Dhar \\ Department of Obstetrics and Gynecology, Christian Medical College and Hospital, Ludhiana, Punjab, India \\ Received: 04 August 2021 \\ Accepted: 02 September 2021 \\ *Correspondence: \\ Dr. Alpana Jacob, \\ E-mail: alpanaj_14@yahoo.co.in \\ Copyright: ( $)$ the author(s), publisher and licensee Medip Academy. This is an open-access article distributed under \\ the terms of the Creative Commons Attribution Non-Commercial License, which permits unrestricted non-commercial \\ use, distribution, and reproduction in any medium, provided the original work is properly cited.
}

\begin{abstract}
Background: Blood transfusion is an essential lifesaving component in obstetrics. Extra blood loss in pregnancy can occur due to various gestational disorders and complications during labour and delivery. Reduction in maternal morbidity and mortality has been observed by increased use of comprehensive emergency obstetrics care in which blood transfusion has achieved recognition as one of the important components. In a developing country like India, the need for well maintained and readily available blood and transfusion services becomes paramount to decrease maternal morbidity and mortality. We wanted to determine the clinical characteristics and indication of blood transfusion in obstetrics and also determine any adverse blood transfusion reaction.

Methods: This cross-sectional study was conducted in the department of obstetrics and gynaecology, Christian medical college, Ludhiana for a period of eighteen months from 15th October 2018. The study group included all the antenatal and postnatal patients up to 6 weeks postpartum who were admitted in the obstetric unit, requiring blood or component transfusions. Clinical characteristics, indication of blood transfusion and any adverse blood transfusion reaction were recorded.

Results: In our study, about $7.84 \%$ of obstetric admission required blood and blood components. Most common indication for blood transfusion was anaemia either during antenatal or during postnatal period (33.91\%). Majority of the patients were unbooked antenatally $(63.91 \%)$ and were multiparous $(93.91 \%) .4$ or more blood transfusions were given in $28.26 \%$ of cases.

Conclusions: Blood transfusion is live saving measure in many obstetric patients. Blood transfusion is an essential component of emergency obstetric care and appropriate blood transfusion significantly reduces maternal mortality. Severe anaemia is the most common condition requiring blood transfusion, which may be chronic due to nutritional deficiency or following acute blood loss, followed by postpartum haemorrhage, placental abruption and placenta previa. Availability of transfusion facility and blood products in obstetric care setting in peripheral health centres can reduce need for referral of patients and indirectly reduce the maternal morbidity and mortality.
\end{abstract}

Keywords: Blood transfusion, Obstetric complications, Maternal outcome, Adverse blood reaction

\section{INTRODUCTION}

Blood transfusion is an essential component in obstetrics and at times live saving. The reported transfusion rate in obstetrics varies from $0.6 \%$ to $6 \%$. Variations in transfusion rates are seen in different complications. Anaemia is the most common haematological disorder that may occur in pregnancy and is a significant cause of maternal morbidity and mortality in India. The decision of blood transfusion should be made on both clinical and haematological grounds. Transfusion is almost always indicated when haemoglobin $(\mathrm{Hb})$ is less than $7 \mathrm{gm} / \mathrm{dl}$ to reduce the rate of maternal morbidity and mortality., Postpartum haemorrhage and anaemia in pregnancy are 
the two most important factors requiring blood transfusion. Other causes include: placental complications like placenta previa, abruptio placentae, placenta accreta and retained placenta, conditions causing overdistension of uterus like polyhydramnios or multiple pregnancies, preeclampsia, disseminated intravascular coagulation (DIC), preterm labour. Even augmentation of labour and operative delivery (both vaginal and abdominal) puts patient at a risk of requiring blood transfusion. ${ }^{3,4}$

Life threatening haemorrhages occur in $0.1 \%$ of deliveries and massive haemorrhages occur in $3-5 \%$ of deliveries. $^{5}$ There is enhancement of coagulation and inhibition of fibrinolytic system during pregnancy so that, when there is a massive blood loss it will result in loss of coagulation factors which will cause more bleeding and thus, result into a vicious cycle which will ultimately cause DIC. Haemorrhages in DIC are massive which sometimes require replacement of $50 \%$ of total blood volume in 3 hours or whole blood volume in a duration of 24 hours which is known as massive blood transfusion. In such cases, massive transfusion protocols are required which helps a treating obstetrician in deciding a judicious use of blood components. ${ }^{5,6}$

It is important to order limited amount of blood units to minimise the wastage of blood and its components. There are situations in which blood transfusion can be absolutely avoided. Arranging one unit of blood to combat a possible loss of one unit of blood intraoperatively is unnecessary because loss of one unit of blood neither causes any significant hypovolemia nor does it induce tissue hypoxia, however its application in obstetrics can vary. Volume depletion by $10 \%$ (loss of 1 unit of blood) can be safely and effectively treated by infusion of crystalloid solution. Therefore, it is necessary to use blood transfusion only in cases of absolute indications. ${ }^{7}$ Secondly, the use of BT has been associated with many immediate complications and long-term complications. The immediate complications of BT include haemolytic reactions (occurs within minutes of starting BT) due to error of transfusion of different blood group. This manifests in form of rash, fever, chills and rigors flank pain, hyperkalaemia, hypotension, DIC and acute renal failure. ${ }^{8}$

Other serious fatal complication resulting due to fluid overload is transfusion related acute lung injury (TRALI). It manifests within 2-6 hours of blood transfusion as acute respiratory distress syndrome (ARDS). It is a leading cause of death related to blood transfusion in United States. ${ }^{8}$ The long-term complications of BT include transmission of serious chronic fatal infections through the blood. Although the incident of HIV, Hepatitis $B$ and $C$ have reduced drastically due to the screening of blood, Creutzfeldt-Jakob disease and Chagas disease (trypanosomiasis) is an emerging concern because the parasite can survive cryopreservation of blood products. Bacterial contamination of blood with
Yersinia and Staphylococcus aureus is most common and it leads to septicaemia in patients and ultimately results in mortality. ${ }^{8}$ Despite all measures taken to prevent such complications, they still occur in about $1 \%$ of transfusions. Hence, when no other alternatives are available and when benefits outweigh the risks involved then only the decision for transfusion should be taken. ${ }^{8-10}$

\section{Objectives}

Objectives of current study were; to determine clinical characteristics and indication of blood transfusion in obstetrics and to determine any adverse blood transfusion reaction.

\section{METHODS}

This is a cross-sectional study conducted over a period of 18 months from 15 October 2018 in the department of obstetrics and gynaecology, Christian medical college and hospital, Ludhiana. Punjab. All antenatal and postnatal cases (up to 6 weeks) requiring blood transfusions, who were getting admitted under obstetric unit were included in the study.

\section{Sample size}

Using the equation for calculation of sample size for frequency in a population:

$$
\begin{aligned}
\text { Sample size }=\mathrm{n} & =[\mathrm{DEFF} * \mathrm{~Np}(1-\mathrm{p})] /[(\mathrm{d} 2 / \mathrm{Z} 21 \\
& -\alpha / 2 *(\mathrm{~N}-1)+\mathrm{p} *(1-\mathrm{p})] 11
\end{aligned}
$$

Where; population size (for finite population correction factor or fpc) $(\mathrm{N})=800$, hypothesized $\%$ frequency of outcome factor in the population $(\mathrm{p})=5 \% \pm 5$, confidence limit as $\%$ of 100 (absolute $\pm \%$ ) (d) $=5 \%$, design effect (for cluster surveys-DEFF) $=1$. The minimum sample of subjects required to be studied is 212 . Allowing for $10 \%$ non-response in this cross-sectional study, a minimum of 230 patients were included in this study. Detailed demographic obstetric history from all the cases and detailed information was explained to the patients according to the protocol and a written consent was obtained. For all those who require blood and blood products transfusion, the details of the procedure were explained, and a written consent was taken from the patient. As per the guidelines, prior to transfusion, vitals were recorded for all the patients. Cross checking for name, hospital unit number, blood group, blood bag number, date of expiry of blood bag and date of collection of blood was done. After cross checking, when the results are found to be correct, the blood transfusion was started. All transfusion was given and monitored closely for first 15 minutes for acute adverse blood transfusion reaction, with monitoring of the vital signs every 30 minutes. Blood or blood products were 
transfused within 4 hours. In case of any blood transfusion reaction, the transfusion process was stopped, blood bank authority was notified and blood bag was sent back to blood bank for re-cross checking. All patients were followed up for next 24 hours after blood transfusion, to monitor development of any adverse reaction.

\section{Statistical analysis}

Data was entered in the Microsoft Excel software and analyzed by Statistical Package for Social Sciences (SPSS version 21). Calculations were done for frequency, proportions, mean, and standard deviation. Chi-square test was applied to determine statistical significance. Relative risk and its $95 \%$ confidence interval was calculated wherever appropriate.

\section{RESULTS}

A total of 2935 patients were admitted in obstetric unit of our hospital. Out of which, two hundred and thirty patients $(7.84 \%)$ required blood and blood products. The mean age of the patients in the study was 27.14 years. Maximum patients belonged to the age group 21-30 years $(67.39 \%)$ followed by $31-40$ years $(26.52 \%)$. Among 230 patients requiring blood transfusion, $83(36.09 \%)$ cases were antenatal booked cases while majority 147 (63.91\%) were unbooked. Majority of the patients were multiparous $(93.91 \%)$ followed by nulliparous $(6.09 \%)$. In the present study, majority of the patients received antenatal blood transfusion $(42.17 \%)$, followed by postnatal $(27.39 \%)$, intrapartum/intraoperatively (19.56), $6.08 \%$ transfusion were given in abortions, and $4.78 \%$ in ectopic pregnancy. Emergency lower segment caesarean section (LSCS) was the leading mode of delivery followed by normal vaginal delivery $(30 \%)$, dilatation \& evacuation $(6.09 \%)$, ectopic pregnancy $(4.78 \%)$, elective LSCS $(3.91 \%)$, ruptured uterus $(2.60 \%)$, forceps delivery $(1.74 \%)$, and undelivered $(1.30 \%)$. A total of $87.39 \%$ patients delivered in our institution and $12.61 \%$ of the patients delivered outside and were referred to us postpartum. In the present study, most common indication for blood transfusion was anaemia either during antenatal, or during postnatal period $(33.91 \%)$ for blood transfusion. Postpartum haemorrhage (19.99\%), antepartum haemorrhage $(19.13 \%)$, thrombocytopenia $(8.26 \%)$, abortions $(6.08 \%)$, ectopic pregnancy $(4.78 \%)$, ruptured uterus $(2.60 \%)$, DIC $(2.60 \%)$, thalassemia $(1.30 \%)$ and morbidly adherent placenta $(1.30 \%)$.

Transfusion with packed red blood cells (PRBCs) was the most common component $(92.61 \%)$, followed by fresh frozen plasma (FFP) (26.52\%), platelet concentrates $(13.91 \%)$ and cryoprecipitate $(0.43 \%)$. Many patients required more than one blood component. Massive blood transfusion was seen in only 5 patients $(2.17 \%)$. It was observed that $68.26 \%$ patients were transfused with packed red blood cells, $13.91 \%$ patients were transfused with PRBCS and FFP, $7.83 \%$ patients were transfused with PRBCS, FFP and platelet concentrates, $3.91 \%$ were transfused with FFP, 3.04\% were transfused with platelet concentrates, $2.17 \%$ were transfused with PRBCs and platelet concentrates, very small percentage of patients were transfused with FFP, platelet concentrates $(0.43 \%)$ and PRBCs, FFP, platelet concentrates, cryoprecipitate $(0.43 \%) .4$ or more blood transfusions were given in $28.26 \%$, followed by $35.22 \%$ of patients who were given 2 units of blood transfusion, and 1 unit in $28.26 \%$ of patients, $23(10.00 \%)$ out of 230 patients required 3 units of blood transfusions. Adverse blood transfusion reaction was seen only in 9 out of 230 patients (3.91\%) and majority (96.09\%) of them had no adverse reaction. Minor adverse transfusion reactions like chills was seen in $1.30 \%$, followed by nausea $(0.87 \%)$, oedema $(0.87 \%)$, fever $(0.43 \%)$, and chest pain in $0.43 \%$.

Table 1: Distribution of patients according to various parameters $(n=230)$.

\begin{tabular}{|c|c|c|}
\hline Parameters & Frequency & $\%$ \\
\hline \multicolumn{3}{|c|}{ Distribution of patients according to age (years) } \\
\hline$<20$ & 8 & 3.48 \\
\hline $20-30$ & 155 & 67.39 \\
\hline $31-40$ & 61 & 26.52 \\
\hline $41-50$ & 6 & 2.61 \\
\hline Mean \pm SD & $27.14 \pm 5.3$ & \\
\hline Median (25th- $75^{\text {th }}$ percentile $)$ & $26(23-30)$ & \\
\hline Range & $18-49$ & \\
\hline \multicolumn{3}{|c|}{ Distribution of patients according tobooking status } \\
\hline Booked & 83 & 36.09 \\
\hline Unbooked & 147 & 63.91 \\
\hline \multicolumn{3}{|c|}{ Distributionof patients according to parity } \\
\hline Nulliparous & 14 & 6.09 \\
\hline Multiparous & 216 & 93.91 \\
\hline \multicolumn{3}{|c|}{$\begin{array}{l}\text { Distribution of patients according to timing of blood } \\
\text { transfusion gestation }\end{array}$} \\
\hline Ectopic & 11 & 4.78 \\
\hline Abortions & 14 & 6.08 \\
\hline Antenatal & 97 & 42.17 \\
\hline Intrapartum/Intraoperative & 45 & 19.56 \\
\hline Postnatal & 63 & 27.39 \\
\hline \multicolumn{3}{|l|}{ Mode of delivery } \\
\hline Ectopic (surgical intervention) & 11 & 4.78 \\
\hline $\mathrm{D}$ and $\mathrm{E}$ & 14 & 6.09 \\
\hline Normal vaginal delivery & 69 & 30 \\
\hline Forceps & 4 & 1.74 \\
\hline \multicolumn{3}{|c|}{$\begin{array}{l}\text { Distributionof patients inrelation to termination of } \\
\text { pregnancy }\end{array}$} \\
\hline Elective LSCS & 9 & 3.91 \\
\hline Emergency LSCS & 114 & 49.56 \\
\hline Ruptureuterus (Laparotomy) & 6 & 2.60 \\
\hline Undelivered & 3 & 1.30 \\
\hline \multicolumn{3}{|c|}{ Distribution of patients accordingto place of delivery } \\
\hline $\mathrm{CMC}$ & 201 & 87.39 \\
\hline Outside & 29 & 12.61 \\
\hline
\end{tabular}


Table 2: Distribution of patients according to obstetrics disorder requiring blood transfusion $(\mathbf{n}=\mathbf{2 3 0})$.

\begin{tabular}{|c|c|c|}
\hline $\begin{array}{l}\text { Obstetric disorders requiring } \\
\text { blood transfusion }\end{array}$ & Frequency & $\%$ \\
\hline Anemia & 78 & 33.91 \\
\hline \multicolumn{3}{|l|}{ PPH } \\
\hline Atonic & 40 & 17.39 \\
\hline Traumatic & 6 & 2.60 \\
\hline \multicolumn{3}{|l|}{ APH } \\
\hline Placentalabruption & 23 & 10.0 \\
\hline Placentaprevia & 21 & 9.13 \\
\hline Thrombocytopenia & 19 & 8.26 \\
\hline Abortions & 14 & 6.08 \\
\hline EctopicPregnancy & 11 & 4.78 \\
\hline Ruptureuterus & 6 & 2.60 \\
\hline $\mathrm{DIC}$ & 6 & 2.60 \\
\hline Thalassemia & 3 & 1.30 \\
\hline Morbidityadherentplacenta & 3 & 1.30 \\
\hline
\end{tabular}

Table 3: Distribution of type of blood products transfused of study subjects $(n=230)$.

\begin{tabular}{|lll|}
\hline $\begin{array}{l}\text { Type of blood products } \\
\text { transfused }\end{array}$ & Frequency & $\%$ \\
\hline PRBCS & 157 & 68.26 \\
\hline PRBCS+FFP & 32 & 13.91 \\
\hline $\begin{array}{l}\text { PRBCS+FFP+platelet } \\
\text { concentrates }\end{array}$ & 18 & 7.83 \\
\hline FFP & 9 & 3.91 \\
\hline Platelet concentrates & 7 & 3.04 \\
\hline $\begin{array}{l}\text { PRBCS+platelet } \\
\text { concentrates }\end{array}$ & 5 & 2.17 \\
\hline FFP+platelet concentrates & 1 & 0.43 \\
\hline $\begin{array}{l}\text { PRBC+FFP+platelet } \\
\text { concentrates+cryoprecipitat } \\
\text { e }\end{array}$ & 1 & 0.43 \\
\hline
\end{tabular}

Table 4: Distribution of patients according to various parameters, blood transfusion requirements and blood transfusion reactions $(n=230)$.

\begin{tabular}{|c|c|c|}
\hline Parameters & Frequency & $\%$ \\
\hline \multicolumn{3}{|c|}{ Number of blood unit requirement of study subjects } \\
\hline 1 & 65 & 28.26 \\
\hline 2 & 81 & 35.22 \\
\hline 3 & 23 & 10.00 \\
\hline 4 and more & 61 & 26.52 \\
\hline \multicolumn{3}{|c|}{$\begin{array}{l}\text { Distribution of patients according to indication of } \\
\text { massive transfusion }(\mathrm{N}=5)\end{array}$} \\
\hline APH & 1 & 20 \\
\hline DIC & 1 & 20 \\
\hline Placenta acreeta & 3 & 60 \\
\hline \multicolumn{3}{|c|}{$\begin{array}{l}\text { Distribution of patients according to incidence of } \\
\text { adverse blood transfusion reaction of study subjects }\end{array}$} \\
\hline Yes & 9 & 3.91 \\
\hline
\end{tabular}

\begin{tabular}{|c|c|c|}
\hline Parameters & Frequency & $\%$ \\
\hline No & 221 & 96.09 \\
\hline \multicolumn{3}{|c|}{$\begin{array}{l}\text { Distribution of patients according to incidence of } \\
\text { blood transfusion reaction Generalises (blood } \\
\text { transfusion reaction) }\end{array}$} \\
\hline \multicolumn{3}{|l|}{ Generalised } \\
\hline Fever & 1 & 0.43 \\
\hline Chills & 3 & 1.30 \\
\hline Nausea & 2 & 0.87 \\
\hline Edema & 2 & 0.87 \\
\hline Chestpain & 1 & 0.43 \\
\hline
\end{tabular}

\section{DISCUSSION}

The present study was a cross-sectional study on 230 antenatal and postnatal women, with an aim to determine the clinical characteristics and indication of blood transfusion in obstetrics. In our study, BT was required in 230/2935 (7.84\%) women. Compared to our study, Vimal et al reported that blood transfusion was required in $35.84 \%$ patients. ${ }^{12}$ In the study by Bangal et al $5.33 \%$ of obstetric admissions needed transfusion of blood or its components. ${ }^{13}$ Akingbola et al reported that the overall transfusion rate was $2.2 \% ; 78.7 \%$ were transfused at delivery and $22.3 \%$ were transfused during pregnancy. ${ }^{14}$ The rate of requirement of blood in the studies may vary due to the complexity of cases observed at the facility, due to its status as a tertiary institution as well as referral centre and booking status. This difference in findings of studies could also be explained by different transfusion practices among institutions, low availability of donor blood in our environment, or case mix. Ideally, minimal blood use is recommended in standardized healthcare facilities.

\section{Age}

The mean age of the patients in the present study was $27.14 \pm 5.3$ years with $67.39 \%$ of patients belonging to age group 20 - 30 years followed by 31-40 years (26.52\%), $<20$ years $(3.48 \%)$. This was similar to a study by Chowdhury et al in which the most common age group was 20-30 years. ${ }^{15}$ Among other studies, Agrawal et al reported that mean age of the patients was 27.4 years. In the study by Renuka et al $70.16 \%$ women were in the age group of 21 to 30 years. ${ }^{16,17}$ Vaid et al reported mean age of 27.7 years. ${ }^{18}$

\section{Booked deliveries}

In the present study, majority $(63.91 \%)$ of patients were unbooked and only 83 out of 230 patients $(36.09 \%)$ were booked. In another study conducted at tertiary care center in India by Agarwal et al there were a significant number of women who did not receive any antenatal care during pregnancy ( $42 \%$ excluding the early pregnancy cases). In the study by Renuka et al $40.69 \%$ women were booked, and Vaid et al reported $69.14 \%$ patients to be booked and Madhushree et al $32.35 \%$ women were booked. ${ }^{17-19}$ 
Lack of antenatal care is associated with a significant increase in maternal and neonatal morbidity and mortality. The causes for lack of prenatal care include socio-economic factors, educational status, access to healthcare facility and quality of healthcare. Improving awareness regarding the importance of family welfare services and strengthening the quality of services is the only way forward.

\section{Parity}

In present study, $14(6.09 \%)$ were nulliparous and 216 (93.91\%) were multiparous. Among other studies, in the study by Agrawal et al majority (54\%) of the patients were para 2 or more. ${ }^{16}$ Renuka et al reported that $58.37 \%$ women were multigravida and Chowdhury et al reported that $68.35 \%$ women were multiparous. ${ }^{15,17}$

\section{Mode of delivery}

Among the obstetrical patients who required blood transfusion, majority $(49.56 \%)$ of patients had emergency LSCS, 30\% had normal vaginal delivery, 6.09\% had dilatation \& evacuation, $4.78 \%$ had ectopic pregnancy, $3.91 \%$ had elective LSCS, $1.74 \%$ had forceps delivery, $2.60 \%$ had ruptured uterus who underwent laparotomy and $1.30 \%$ of patients who received blood transfusion did not come back to the institution for delivery. Among other studies, Agrawal et al reported that the mode of delivery was vaginal in $21 \%$ of cases and caesarean in $79 \%$ of cases. ${ }^{16}$ Most of the women were delivered by caesarean section $(58.56 \%)$ in the study by Renuka et al. ${ }^{17}$ Similarly in study by Chowdhury et al $63.92 \%$ had caesarean section. ${ }^{15}$ In Thurn et al $5.7 \%$ cases had caesarean deliveries. ${ }^{20}$ The demographics of the study population of the present study and other comparative studies has been shown in (Table 1). Patients who received blood and its components belonged to unbooked cases. This could be due to the fact that most of the patients with obstetric emergencies were referred to the hospital from periphery with obstetrical complications requiring blood transfusion especially obstetric haemorrhage. The study demographics present an interesting finding that most of the patients.

\section{Obstetric disorders requiring blood transfusion}

Several conditions which need blood transfusion in obstetrics are bleeding in $1^{\text {st }}$ trimester (abortion, ectopic, and molar pregnancy), antepartum haemorrhage, postpartum haemorrhage, severe anaemia, thrombocytopenia, hemoglobinopathy and DIC. The requirement for transfusion can be decreased by prevention/treatment of anaemia and blood loss. However, there are limitations for prevention and blood transfusion becomes essential. ${ }^{17}$ In the present study, majority of the patients received blood transfusion during antenatal period, followed by postnatal (27.39\%), intrapartum/intraoperative (19.56\%), abortions (6.08\%), and ectopic pregnancy $(4.78 \%)$. In the present study, among the various causes of requirement of blood, anaemia was the most common cause $(33.91 \%)$. Anaemia during pregnancy is common because of an increase in blood volume. During pregnancy, more iron is needed primarily to supply the growing fetus and placenta and to increase the maternal red cell mass. Although iron deficiency is the most common cause of anaemia, infection, genetic factors, and many other conditions can also lead to anaemia. Anaemia during pregnancy is a significant cause of maternal mortality and morbidity. ${ }^{21}$ Our findings were in line with the study by Akingbola et al who mentioned that the most common indication for blood transfusion was anaemia $(65.5 \%) .{ }^{14}$ Even Bangal et al reported that severe anaemia either during pregnancy or during postpartum period was most common indication $(36.55 \%)$ for blood transfusion. ${ }^{13}$ The findings are also supported by Renuka et al where severe anaemia either during pregnancy or during postpartum period was the most common indication $(39.96 \%)$ for transfusion. ${ }^{17}$

In current study, second common cause was post-partum haemorrhage $(20 \%)$, out of which 40 patients had atonic PPH and 6 patients had traumatic PPH. PPH is usually troublesome as it can cause massive haemorrhage. Similar to present study, PPH was the second common cause of BT $(32.6 \%)$ in the study by Akingbola et al. ${ }^{14}$ In study by Bangal et al accidental haemorrhage was the second most common cause $(20.92 \%) .{ }^{13}$ Even in a similar study by Renuka et al postpartum haemorrhage was the second common cause for blood transfusion present in $21.54 \%$ patients. ${ }^{17}$ However, Vaid et al reported that severe anaemia was the second common cause for blood transfusion (29.88\% patients) with the commonest cause being PPH (35.56\% patients). ${ }^{18}$ Other causes of BT in our study included placental abruption (10\%) and placenta previa in $9.13 \%$. The other less common causes were thrombocytopenia, abortions, ectopic pregnancy, ruptured uterus, DIC, thalassemia and morbidity adherent placenta. $^{18}$

Among other studies, Akingbola et al reported other causes of BT as severe malaria in $0.7 \%$ patients, placenta previa in $0.7 \%$, and abruptio placenta in $0.5 \%$ patients. ${ }^{14}$ In study by Bangal et al other causes of BT were placenta praevia $(5.3 \%)$ and ruptured ectopic pregnancy $(5.03 \%) .^{13}$ Less common indications were abortions, complications of third stage of labour, vesicular mole evacuation etc. Renuka et al reported that other common causes of BT were placenta previa (12.33\%), DIC $(9.76 \%)$ and ectopic pregnancy $(3.68 \%)$ with less common indications being abortions, vesicular mole, thrombocytopenia, medical disorders like liver disease, renal disease etc. Vaid et al reported that other common causes for blood transfusion were early trimester haemorrhage (19.5\%) and antepartum haemorrhage $(13.58 \%) \cdot{ }^{17,18}$

\section{Massive blood transfusion}

In the present study, massive BT was required in 5 $(2.17 \%)$ patients. Among other studies, Thurn et al 
reported that massive BT was needed in $5.3 \%$ patients. ${ }^{20}$ The incidence of massive transfusion in obstetric patients has been reported to be 2.3-9.1 per 10000 deliveries. $^{21-24}$ Different definitions of massive transfusion, different transfusion policies, and method of data collection might explain the wide discrepancy. The following table enlists the causes of BT in our study and other studies.

\section{Type of blood products required}

The blood products transfused to the patients varied depending upon the requirements and the guidelines. The different components of the blood play different functions and thus their use is very specific and has overpowered the use of whole blood. FFP is used in correction of microvascular bleeding, multiple coagulation factor deficiencies, massive transfusion with coagulation abnormalities. Fresh frozen plasma is very useful in the management of accidental haemorrhage and cases with massive blood loss as it prevents or controls dreadful complications like DIC. It also helps in preventing other complications like acute renal failure and shock. Platelet concentrates are used when the platelet counts fall below $20,000 / \mathrm{mm} 3$ with one unit of platelets increasing the platelet count by 50007000/cumm.75 packed red blood cells should be used in obstetric emergencies rather than whole blood for transfusion as whole blood leads to increased plasma volume, thus causing circulatory overload. ${ }^{17}$

We noted that in majority of patients, type of blood products transfused were PRBCs $(92.61 \%)$ followed by FFP (26.52\%), platelet concentrates (13.91\%) and cryoprecipitate in only 1 out of 230 patients $(0.43 \%)$. The products were administered in various combinations to manage both the coagulation status and the fluid status. In the previous studies, Akingbola et al reported that $84.6 \%$ patients were transfused with whole blood or blood products with $82.5 \%$ of them receiving whole blood, $0.9 \%$ received fresh frozen plasma, $0.9 \%$ received packed cell blood, and $0.4 \%$ received cryoprecipitate. $15.4 \%$ had a combination of blood and blood products. In the study by Chawla et al $79 \%$ patients were transfused with PRBC, $66 \%$ with FFP, and $15 \%$ with platelet concentrate. In the study by Renuka et al $61.67 \%$ received packed cells, $18.64 \%$ received platelets, $11.49 \%$ received fresh frozen plasma, $7.49 \%$ received whole blood and $0.69 \%$ received cryoprecipitate. ${ }^{15,17}$ Patel et al reported that $80 \%$ patients were transfused with PCV only and $20 \%$ patients received combination of blood and blood products like FFP, PRC, and cryoprecipitate. The following table shows the use of blood products in our study and other studies. ${ }^{10}$

\section{Number of blood units required}

In the present study, $35.22 \%$ patients required 2 units of blood transfusion, followed by $28.26 \%$ of single unit of blood transfusion, 4 or more units in $26.52 \%$ and 3 unit of blood transfusions in $10 \%$ of patients. In comparison to our study, Bangal et al also used 2 units of blood in maximum number of women $(37.74 \%)$ followed by three units in $25.96 \%$, one unit in $13.77 \%$ and 4 or more units in $9.93 \%$ women. ${ }^{13}$ Renuka et al also used 2 units of blood in maximum number of women $(39.96 \%)$ followed by three units in $24.86 \%$, one unit in $21.17 \%$ and 4 or more units in $13.99 \%$ women. ${ }^{13,17}$ On the other hand, Chowdhury et al used single unit of blood transfusion in majority of the women $(69.62 \%)$, followed by 2 units in $16.46 \%$, three units in $7.6 \%$ and 4 or more units in $3.8 \%$ women. ${ }^{15}$

\section{Adverse blood transfusion reactions}

For the purpose of BT, an initial screening and cross matching of the blood is done for preventing any sideeffects. There were no major adverse effects during the study period. However, there were some minor adverse reactions after the transfusion in $3.91 \%$ women which included chill $(1.30 \%)$, nausea $(0.87 \%)$, oedema $(0.87 \%)$ and fever $(0.43 \%)$. The side effects were minor and were managed effectively. In a review article by Chhabra et al on rational use of blood and its components in obstetrics gynaecological practice, it was stated that $1 \%$ of all the transfusions lead to some adverse reaction; and so this has to be kept in mind while transfusing the women in obstetric practice. ${ }^{8}$ Among other studies, Vaid et al reported that the adverse reactions of blood transfusions were seen in $1.95 \%$ of total patients. ${ }^{18}$ Shivering and fever $(0.74 \%)$ were the most common adverse reaction as seen in the present study. Renuka et al reported that $5.34 \%$ patients out of 543 women had a transfusion reaction while $94.65 \%$ had none. ${ }^{17}$ Out of 29 women, 7 $(1.2 \%)$ had a major transfusion reaction in the form of transfusion related acute lung injury (TRALI), while remaining had minor transfusion reactions such as urticarial rash and chills. There were 3 deaths in the present study which were due to varying reasons such as multiorgan failure, sepsis and shock. Among other studies, Agarwal et al reported that the number of maternal deaths occurring amongst all women with massive obstetric haemorrhage was $3.33 \% .{ }^{16}$ No mortality was reported by Chawla et al, Vaid et al and Renuka et al. ${ }^{17,18,25}$

\section{CONCLUSION}

Blood transfusion is an essential component of emergency obstetric care and appropriate blood transfusion significantly reduces maternal mortality. Blood transfusion is life-saving in many obstetric patients especially in obstetric haemorrhage (antepartum haemorrhage, postpartum haemorrhage). Acute obstetric blood loss is usually unpredictable and sudden. Severe anaemia is the most common condition requiring blood transfusion, which may be chronic due to nutritional deficiency or following acute blood loss, followed by postpartum haemorrhage, placental abruption and placenta previa. The use of blood products such as packed red blood cells, fresh frozen plasma and platelet 
concentrates have overtaken the use of whole blood. A well-functioning blood bank is very important for providing blood and blood products in emergency. Blood transfusion possesses a threat of transfusion reactions; so judicious use of blood and blood products is advisable. Availability of transfusion facility and blood products in obstetric care setting in peripheral health centres can reduce need for referral of patients and indirectly reduce the maternal morbidity and mortality.

\section{ACKNOWLEDGEMENTS}

Authors are thankful to Dr. Kavita Mandrelle, professor and head of department, department of obstetrics and gynaecology, for guidance during the conduct of the study.

Funding: No funding sources

Conflict of interest: None declared

Ethical approval: The study was approved by the Institutional Ethics Committee

\section{REFERENCES}

1. Murphy MF, Wallington TB, Kelsey P. Guidelines for the clinical use of red cell transfusions. $\mathrm{Br} \mathrm{J}$ Haematol. 2001;113(1):24-31.

2. United Kingdom Blood Services. Blood transfusion. In: McClelland DBL, eds. Handbook of transfusion medicine. 3rd ed. London: The Stationary Office; 2001.

3. Eyelade OR, Adesina OA, Adewole IF, et al. Blood transfusion requirement during caesarean delivery: risk factors. Ann Ib Postgrad Med. 2015;13(1):29-35.

4. Bates I, Chapotera GK, McKew S, et al. Maternal mortality in sub-Saharan Africa: the contribution of ineffective blood transfusion services. $\mathrm{Br} \mathrm{J}$ Obstet Gynaecol. 2008;115(11):1331-9.

5. Millar C, Laffan M. Hemostatic changes in normal pregnancy. In: Cohen H, O'Brien P, eds. Disorders of thrombosis and hemostasis in pregnancy: a guide to management. London: Springer; 2015:1-13.

6. Prevention of postpartum hemorrhage initiative. Available at: http://www.pphprevention.org/pph.php. Accessed on 20 October 2020.

7. Asif N, Hassan K, Ikram N. Judicious use blood and its components. J Islamabad Med Dent College. 2013; 2(1):49-52.

8. Chhabra S, Namgyal A. Rationale use of blood and its components in obstetric-gynecological practice. J Mahatma Gandhi Inst Med Sci. 2014;19(2):93-9.

9. Prata N, Hamza S, Bell S. Inability to predict postpartum hemorrhage: insights from Egyptian intervention data. BMC Pregnancy Childbirth. 2011; 11:97.

10. Patel VP, Patel RV, Shah PT. Study of role of blood transfusion in obstetric emergencies. Int $\mathrm{J}$ Reprod Contracept Obstet Gynecol. 2014;3(4):1002-5.
11. Transfusion guidelines. Available at: https://transfusionguidelines.org.uk/. Accessed on 20 October 2020.

12. Vimal M, Rakesh B, Anandbaskar N. Pattern of utilization of blood and blood products in a tertiary care hospital. Rec Adv Path Lab Med. 2019;5(2):147.

13. Bangal VB, Gavhane SP, Aher KH. Pattern of utilization of blood and blood components in obstetrics at tertiary care hospital. Int $\mathbf{J}$ Reprod Contracept Obstet Gynecol. 2017;6(10):4671-6.

14. Akingbola TS, Bello O. Obstetric emergencies and transfusion needs in a Nigerian hospital. HematolTransfus Int J. 2016;2(6):107-10.

15. Chowdhury F, Akhter S, Islam A. Evaluation of blood transfusion practices in obstetrics and gynecology in a tertiary hospital in Bangladesh. J Bangladesh Coll Physic Surg. 2016;34(1):9-14.

16. Agrawal S, Singh A, Biswas R. Retrospective review of maternal deaths and maternal near misses due to major obstetric haemorrhage at a tertiary care centre in India. Int J Reprod Contracept Obstet Gynecol. 2019;8(8):3431-4.

17. Renuka, Shridevi AS, Patil GL. Blood transfusion needs among obstetric patients in a tertiary care hospital: a prospective observational study. Int J Reprod Contracept Obstet Gynecol. 2019;8(11):42449.

18. Vaid P, Kapoor B, Kapoor M. Role of blood and blood components transfusion in obstetric emergencies. Int $\mathbf{J}$ Reprod Contracept Obstet Gynecol. 2020;9(5):2029-34.

19. Madhushree D, Metgud MC, Patil K. Retrospective analysis of all patients undergoing blood transfusion in obstetrics at a tertiary care hospital, Belgaum: a cross-sectional study. Indian J Health Sci Biomed Res. 2018;11(2):116-20.

20. Thurn L, Wikman A, Westgren M. Massive blood transfusion in relation to delivery: incidence, trends and risk factors: a population-based cohort study. Br J Obstet Gynaecol. 2019;126(13):1577-86.

21. Abu-Ouf NM, Jan MM. The impact of maternal iron deficiency and iron deficiency anemia on child's health. Saudi Med J. 2015;36(2):146-9.

22. Mhyre JM, Shilkrut A, Kuklina EV. Massive blood transfusion during hospitalization for delivery in New York State, 1998-2007. Obstet Gynecol. 2013;122(6): 1288-94.

23. Green L, Knight M, Seeney FM. The epidemiology and outcomes of women with postpartum haemorrhage requiring massive transfusion with eight or more units of red cells: a national cross-sectional study. Br J Obstet Gynaecol. 2016;123(13):2164-70.

24. Ramler PI, van den Akker T, Henriquez D. Incidence, management and outcome of women requiring massive transfusion after childbirth in the Netherlands: secondary analysis of a nationwide cohort study between 2004 and 2006. BMC Pregnancy Childbirth. 2017;17(1):197. 
25. Chawla S, Bal MHK, Vardhan BS. Blood transfusion practices in obstetrics: our experience. J Obstet Gynaecol. 2018;68(3):204-7.
Cite this article as: Jacob A, Goyal S, Dhar T.

Pattern of utilization of blood and blood components in obstetrics at a tertiary care center: a cross-sectional study. Int J Reprod Contracept Obstet Gynecol 2021;10:3901-8. 